\title{
PENGARUH QUALITY OF WORK LIFE, SELF DETERMINATION, DAN JOB PERFORMANCE TERHADAP WORK ENGAGEMENT KARYAWAN
}

\author{
Ir. Irmawati, Alifa Sri Wulandari Kn. \\ Universitas Muhammadiyah Surakarta \\ Email: irmawati@ums.ac.id
}

\begin{abstract}
This Research aims to identify and empirically examine (1) the effect of quality of work life on the work engagement. (2) the effect of self determination on work engagement. (3) the impact of job performance on work engagement. (4) the effect of Quality of Worklife, Self Determintion, and Job Performance simultaneously on the work engagement. Variables that used in this study were Quality of Worklife, Self Determintion, Job Performanceas independent variables andwork engagementas adependent variable. The sample of this research was 100 employees of PT. Pamor Sinning Mill'sas respondents by random sampling techniques. Methods of data collection by using questionnaires. Data analysis techniques is multiple regression analysis, $F$ test, andt test. The t test showed that all independents variable has partial effect on the dependent variable, while Ftest analysis data finds that there are simultaneously effect of variablesquality of work life, self determination, and job performance on the work Engagement.
\end{abstract}

Keyword: Quality of Worklife, Self Determintion, Job Performance, Work Engagement

\begin{abstract}
Abstrak
Penelitian ini bertujuan untuk menguji dan mengetahui secara empiris (1) pengaruh Quality of Work life terhadap Work engagement (2) pengaruh Self Determination terhadap Work engagement (3) Pengaruh Job Performance terhadap Work engagement (4) pengaruh Quality of Worklife, Self Determintion, dan Job Performance secara simultan terhadap Work engagement. Variabel yang digunakan dalam penelitian ini adalah Quality of Worklife, Self Determintion, dan Job Performance sebagai variabel independen dan Work engagement sebagai variabel dependen.Sampel dalam penelitian ini adalah karyawan PT. Pamor Spinning Mill's sebanyak 100 responden dengan teknik pengambilan sampel random sampling. Metode pengumpulan data menggunakan kuesioner. Teknik analisis data yaitu analisis regresi berganda, uji F, dan uji t. Hasil analisisuji t menunjukkan terdapat pengaruh secara parsial antara variabel independen terhadap variabel dependen sedangkan data uji $\mathrm{F}$ menunjukkanadanya pengaruh secara simultan variabel Quality of Worklife, Self Determintion, dan Job Performance terhadap Work Engagement.
\end{abstract}

Kata Kunci: Kualitas Kehidupan Kerja, Penggambaran Diri Seseorang, Kinerja, Keterikatan Kerja 


\section{Pendahuluan}

Dalam suatu organisasi, sumber daya manusia bukan hanya sebagai alat produksi, namun juga merupakan indikator penting dalam pencapaian tujuan organisasi.Sumber daya manusia merupakan aset organisasi yang sangat vital, karena itu peran dan fungsinya tidak bisa digantikan oleh sumber daya lainnya. Betapapun modern teknologi yang digunakan, atau sebanyak apa dana yang disiapkan, namun tanpa sumber daya yang profesional semuanya menjadi tidak bermakna (Tjutju, 2008 : 62-63).

Salah satu faktor yang paling penting bagi suatu individu dalam bekerja adalah Work Engagement (Keterikatan Kerja). Keterikatan kerja merupakan sebuah konsep yang bisa mencerminkan bahwa seorang individu tersebut memiliki semangat, fokus, dan juga dedikasi yang kuat dalam bekerja di perusahaan tersebut.Ikatan kerja melibatkan karyawan secara penuh atau keseluruhan, baik secara kognitif, atau secara emosi, karena dalam employee engagement dua hal tersebut secara penuh telah dilibatkan untuk membentuk suatu hubungan yang penuh arti. Employee engagement melibatkan seorang pekerja yang secara penuh terlibat dalam pekerjaannya atau dalam kata lain secara total masuk dan berkelut dengan pekerjaan tersebut, sehingga karyawan tersebut mempunyai tanggungjawab yang sangat besar terhadap pekerjaannya.

Dalam pengertian lain, karyawan yang dirinya dilibatkan atau ikut terlibat pada suatu kegiatan diorganisasinya akan merasa bahwa dirinya dibutuhkan dan punya peran penting dalam organisasi, sehingga dengan adanya dukungan secara psikologis dan fisik akan berpengaruh pada dirinya, hingga merasa benar-benar terikat pada organisasi tersebut. Agar karyawan lebih terikat dalam pekerjaannya, maka harus ada dukungan dari pemimpin, dan hubungan dengan pemimpin yang kuat, terutama dalam hal komunikasi. Hal tersebut secara tidak langsung mencerminkan bahwa lingkungan yang sehat juga, dan motivasi dalam kemampuan seseorang terhadap dirinya sendiri akan menaikkan kinerja orang tersebut dalam bekerja, yang secara otomatis akan sangat berpengaruh terhadap peningkatan work engagement seseorang tersebut di dalam perusahaan

Work engagement tersebut memiliki banyak hubungan dengan beberapa faktor yang mempengaruhi. Beberapa faktor tersebut akan di bahas dalam penelitian ini dan akan dibuktikan apakah benar faktor tersebut mempengaruhi terhadap work engagement seseorang atau tidak. Dalam penelitian ini faktor yang akan diteliti antara lain, Job performance(Kinerja), Quality of Work Life (kualitas lingkungan kerja) dan juga Self Determination (penggambaran diri seseorang).

Dengan demikian, work engagement sangat berpotensi positif bagi PT. Pamor Spinning Mill's sebagai objek dalam penelitian.Berdasarkan uraian diatas maka penelitian ini berusaha untuk mengetahui apa saja yang mempengaruhi work engagement tersebut dengan kemudian mengambil judul penelitian "Pengaruh Quality of Work Life, Self Determination, dan Job Performance Terhadap Work Engagement Karyawan di PT. Pamor Spinning Mill's". Penelitian ini bertujuan untuk mengetahui pengaruh secara simultan maupun parsial antara variabel Quality of Work Life, Self Determination, dan Job Performance terhadap Work Engagement Karyawan di PT. Pamor Spinning Mill's

\section{Tinjauan Pustaka}

\section{Keterikatan Kerja(WorkEngagement)}

Saat ini, engagement merupakan salah satu topik manajemen yang hangat diantara perusahaan konsultan dan madia-media bisnis terkenal ( Saks\& Gruman, 2014:155 ). Banyak kalanganberpendapatbahwa workengagement harus menjadi perhatian serius oleh eksekutif bidang SDM maupun eksekutif puncak agar perusahaan dapat bertahan dari dampak krisis saat ini (Mujiasih\& Ratnaningsih, 2007:2). Menurut Mangkuparawira (2011 : 403) yang dimaksud dengan keterikatan adalah kepatuhan seorang karyawan manajemen 
dan non manajemen pada organisasi yang menyangkut visi, misi, dan tujuan perusahaan dalam proses pekerjaannya. Bukannya dalam arti pemahaman saja, namun juga dalam segi pelaksanaan pekerjaannya. Karyawan yang memiliki keterikatan dengan organisasi di cirikan oleh beberapa hal, yakni:(1) sangat memahami visi, misi, dan tujuan program serta peraturan organisasi. (2) menyenangi pekerjaan. mereka. (3) motivasi kerja yang tinggi. (4) selalu meningkatkan mutu kinerja. (5) merupakan sumber gagasan baru. (6) manajer dan karyawan saling menghormati. (7) mampu membangun tim kerja yang handal. (8) merasa sebagai bagian keluarga besar perusahaan. Menurut Mujiasih dan Ratnaningsih (2012:2) dengan mengetahui tingkat work engagement karyawan dan memeliharanya untuk tetap tinggi maka secara umum perusahaan atau organisasi akan diuntungkan dengan berbagai hal seperti: 1) dapat mempertahankan dan meningkatkan produktivitas karyawan karena mereka merasa happy berkarya di perusahaan tersebut,2)membantu mempertahankan karyawan terbaik, karena mereka tidak mudah tergiur dengan tawaran perusahaan lain, 3) membantu pencapaian target perusahaan, karena beberapa studi yang mengkorelasikan antara tingginya work engagement dengan pencapaian target perusahaan membuktikan kebenaran hipotesisnya bahwa korelasinya adalah sangat positif.

\section{Job Performance}

Menurut Tika (2006 : 121) Kinerja (Job Performance) merupakan hasil-hasil fungsi pekerjaan seseorang yang dipengaruhi oleh berbagai faktor untuk mencapai tujuan organisasi dalam periode waktu tertentu. Job performance sangat berkaitan dengan work engagement karena apabila seorang karyawan memiliki work engagement atau keterikatan kerja, maka karyawan tersebut pastiakan mengedepankan kinerja nya dalam melakukan pekerjaannya. Sehingga dapat dikatakan bahwa job performance atau kinerja karyawan berbanding lurus dengan work engagement karyawan dalam suatu perusahaan. Beragam penelitian kinerja telah diteliti sebelumnya. Menurut Tsui et. al. (1997) dalam Devi (2009:31), Fuad Mas'ud melakukan penilaian terhadap kinerja sumber daya manusia berdasarkan perilaku yang spesifik dengan menggunakan sebelas kriteria yaitu: (1) kuantitas kerja karyawan, (2) kualitas kerja karyawan, (3) efisiensi karyawan, (4) standar kualitas karyawan, (5) usaha karyawan, (6) standar profesi karyawan, (7) kemampuan karyawan, (8) kemampuan karyawan menggunakan akal sehat, (9) ketepatan karyawan, (10) pengetahuan karyawan dan (11) kreatifitas karyawan.

\section{Quality of Work Life}

Quality of Work Life atau kualitas lingkungan kerja merupakan teknik manajemen yang mencakup gugus kendali mutu, yang mengungkapkan pentingnya penghargaan terhadap manusia dalam lingkungan pekerjaannya.Adanya kualitas lingkungan kerja ini juga menumbuhkan keinginan para karyawan tetap tinggal dalam suatu organisasi. Apabila seorang karyawan memiliki kualitas lingkungan kerja yang baik, maka ia bisa jadi memiliki work engagement yang tinggi. Namun tidak menutup kemungkinan juga pegawai yang mendapat kualitas lingkungan kerja yang baik memiliki work engagement yang rendah. Menurut Marihot (2007:292) terdapat beberapa unsur penting dalam kualitas kehidupan kerja (Quality of work life) yaitu:(1) Partisipasi kerja yaitu pengikutsertaan karyawan dalam operasi perusahaan dan pengambilan keputusan yang akan membuktikan bahwa karyawan diterima dan dihargai, yang berdampak pada munculnya perasaan memiliki dan perasaan ikut bertanggung jawab pada keberhasilan tujuan perusahaan, (2) pengembangan karir adalah manajemen pada semua bidang dan jenjang harus menaruh perhatian pada pembinaan karir karyawan yang potensial dengan cara pemberian kesempaan yang sama untuk mengikuti program pelatihan dan pengembangan SDM, melaksanakan 
penilaian kinerja secara jujur dan objektif sebagai dasar dalam pemberian bonus dan insentif, pelaksanaan konsultasi karir dan promosi karyawan untuk jabatan yang lebih tinggi, (3) Komunikasi yaitu penciptaan dan pengembangan komunikasi yang efektif yang berfungsi dalam proses pertukaran informasi, (4) kompensasi yang layak dapat memberikan ketenangan dan kesediaan bagi karyawan untuk bekerja secara optimal sebagai bentuk kontribusi bagi perusahaan dalam mencapai tujuan organisasi, (5) kebanggan yaitu rasa bangga akan lahir sebagai wujud penghargaan individu karyaan akan tugas dan kewajiban di perusahaan tempat ia mengabdi.

\section{Self Determination}

Self determination merupakan salah satu konsep yang berkaitan dengan motivasi dan kepribadian manusia. Menurut Ramirez (2007:4) Self Determination adalah suatu perasaan yang terlepas dari keadaan atau hambatan dalam hidup, individu tersebut merasa bahwa dirinya akan mampu mengatasi dan keluar dari suatu hambatan. Seseorang telah dikatakan telah memiliki self determination ketika seseorang tersebut lebih dipengaruhi oleh motivasi dari dalam dirinya sendiri daripada motivasi dari lingkungan eksternal.Hubungan dengan work engagement adalah ketika seorang telah bisa mengontrol self determination itu maka karyawan tersebut dapat dengan spontan menaikkan work engagement mereka.

\section{Metode Penelitian}

Penelitian ini merupakan penelitian kuantitatif. Sumber data dalam penelitian ini adalah data primer yang berupa jawaban kuesioner dari responden.Metode pengumpulan data yang digunakan adalah kuesioner dan juga metode observasi. Ruang lingkup penelitian ini adalah PT. Pamor Spinning Mill's dengan sampel yang digunakan adalah 100 karyawan PT. Pamor Spinning Mill's.
Dalam penelitian ini digunakan pengambilan sampel random sampling, yaitu pengambilan sampel secara acak sehingga dapat memberikan peluang yang sama bagi setiap unsure atau anggota populasi untuk menjadi anggota sampel. Penelitian ini menggunakan alat analisis regresi berganda, uji t dan uji F.

\section{Hasil dan Pembahasan}

Berdasarkan analisis regresi linear berganda, didapat persamaan regresi:

$Y=4,716+0,290 X_{1}+0,322 X_{2}+0,413 X_{3}+e$

Menurut persamaan regresi tersebut, adapun interpretasi yang dapat dijelaskan adalah sebagai berikut:

1. Koefisien konstanta bernilai 4,716; artinya jika Quality of Work Life, Self Determination, dan Job Performance dianggap konstan, maka nilai produktivitas karyawan akan meningkat sebanyak 4,716.

2. Nilai koefisien regresi untuk variabel Quality of Work Life sebesar 0,290. Artinya jika terdapat penambahan 1 nilai Quality of Work Life(X1) dan variabel independen lain nilainya dianggap tetap, maka nilai Work Engagement (Y) akan bertambah sebesar 0,290.

3. Nilai koefisien regresi untuk variabel Self Determination sebesar 0,322. Artinya jika terdapat penambahan 1 nilai Self Determination (X2) dan variabel independen lain nilainya dianggap tetap, maka nilai Work Engagement (Y) akan bertambah sebesar 0,322.

4. Nilai koefisien regresi untuk variabel Job Performance sebesar 0,413. Artinya jika terdapat penambahan 1 nilai Job Performance (X3) dan variabel independen lain nilainya dianggap tetap, maka nilai Work Engagement (Y) akan bertambah sebesar 0,413 . 
Berdasar hasil uji t dan uji F didapat hasil sebagai berikut:

Tabel 3.1 Hasil Uji F

\begin{tabular}{cccc}
\hline Variabel Dependen & $\mathbf{F}_{\text {hitung }}$ & $\mathbf{F}_{\text {tabel }}$ & Simpulan \\
\hline $\begin{array}{c}\text { Produktivitas Karyawan } \\
\text { (Y) }\end{array}$ & 25,428 & 2,70 & Signifikan \\
\hline
\end{tabular}

Sumber: hasil olahan data SPSS 16.0 for Windows, 2017

Berdasarkan dari uji $\mathrm{F}$ menunjukkan bahwa nilai $\mathrm{F}_{\text {hitung }}$ sebesar $25.428>\mathrm{F}_{\text {tabel }}$ sebesar 2,70 dengan probabilitas sebesar 0,000 ( $p_{\text {value }}<0,05$ ).Hal ini berarti terdapatpengaruh secara simultan yang memang nyata terjadi (signifikan) dan tidak diperoleh secara kebetulan antara quality of work life, self determination, dan Job Performance terhadapWork Engagement Karyawan pada PT. Pamor Spinning Mill's di Karanganyar.

Tabel 3.2 Hasil Uji t

\begin{tabular}{ccccl}
\hline Variabel & $\mathbf{t}_{\text {hitung }}$ & $\mathbf{t}_{\text {tabel }}$ & $\boldsymbol{p}_{\text {value }}$ & Simpulan \\
\hline Quality of Work Life $\left(\mathrm{X}_{1}\right)$ & 3.747 & 1,985 & 0.000 & Signifikan \\
Self Determination $\left(\mathrm{X}_{2}\right)$ & 2.158 & 1,985 & 0.033 & Signifikan \\
Job Performance $\left(\mathrm{X}_{3}\right)$ & 3.356 & 1,985 & 0.001 & Signifikan \\
\hline
\end{tabular}

Sumber: hasil olahan data SPSS 16.0 for Windows, 2017

Berdasarkan analisis uji $t$, dapat diketahui bahwa variabel Quality of Work Life memiliki nilai $t_{\text {hitung }}$ sebesar 3,747 , variabel Self Determination memiliki nilai $\mathrm{t}_{\text {hitung }}$ sebesar 2,158 dan variabel Job Performance memiliki nilai $t_{\text {hitung }}$ sebesar 3,356 dengan nilai $t_{\text {tabel }}$ sebesar 1,985 maka Ho ditolak dan $\mathrm{H}_{1}$ diterima karena $\mathrm{t}_{\text {hitung }}>\mathrm{t}_{\text {tabel }}$ yang artinya ada pengaruh ketiga variabel terhadap Work Engagement karyawan diPT. Pamor Spinning Mill's.

\section{Pengaruh Quality of Work Life terhadap Work Engagement}

Quality of Work Life atau kualitas lingkungan kerja merupakan teknik manajemen yang mencakup gugus kendali mutu, yang mengungkapkan pentingnya penghargaan terhadap manusia dalam lingkungan pekerjaannya.Menurut Mangkuparawira (2011 : 403) yang dimaksud dengan keterikatan adalah kepatuhan seorang karyawan manajemen dan non manajemen pada organisasi yang menyangkut visi, misi, dan tujuan perusahaan dalam proses pekerjaannya. Bukannya dalam arti pemahaman saja, namun juga dalam segi pelaksanaan pekerjaannya.

Adanya kualitas lingkungan kerja ini juga menumbuhkan keinginan para karyawan tetap tinggal dalam suatu organisasi. Apabila seorang karyawan memiliki kualitas lingkungan kerja yang baik, maka ia bisa jadi memiliki work engagement yang tinggi. Namun tidak menutup kemungkinan juga pegawai yang mendapat kualitas lingkungan kerja yang baik memiliki work engagement yang rendah.

Sesuai dengan hasil analisis yang telah dilakukan pada penelitian ini pula dapat diketahui bahwa terdapat pengaruh antara Quality of Work Life terhadap Work Engagement karyawan PT. Pamor Spinning Mill's. Melalui hasil dari analisis linier berganda di dapat nilai koefisien regresi yang positif untuk variabel Quality of Work Life terhadap Work Engagement karyawan di PT. Pamor Spinning Mill's. Hal tersebut dapat diartikan bahwa semakin tinggi kualitas kehidupan kerja PT. Pamor Spinning Mill's maka semakin tinggi pula tingkat work engagement karyawan di PT. Pamor Spinning Mill's. Selain itu dari uji t yang telah dilakukan menyatakan bahwa quality of work 
life memiliki pengaruh signifikan secara parsial terhadap work engagement.

Hasil penelitian ini konsisten dengan penelitian yang telah dilakukan oleh Lidya Ribhkha Genta Polii (2015 : 188), Asmaranta Manik, Donata (2016 : 15)yang membuktikan bahwakualitas kehidupan kerja memiliki pengaruh yang signifikan terhadap keterikatan kerja.

\section{Pengaruh Self Determination terhadap Work Engagement}

Self determination merupakan salah satu konsep yang berkaitan dengan motivasi dan kepribadian manusia. Menurut Ramirez (2007:4) Self Determination adalah suatu perasaan yang terlepas dari keadaan atau hambatan dalam hidup, individu tersebut merasa bahwa dirinya akan mampu mengatasi dan keluar dari suatu hambatan.

Menurut hasil analisis yang telah dilakukan pada penelitian ini pula dapat diketahui bahwa terdapat pengaruh signifikan antara Self Determination terhadap Work Engagement karyawan PT. Pamor Spinning Mill's. Melalui hasil dari analisis linier berganda di dapat nilai koefisien regresi yang positif untuk variabel Self determination terhadap Work Engagement karyawan di PT. Pamor Spinning Mill's. Hal tersebut dapat diartikan bahwa semakin tinggi Self determination pada karyawan PT. Pamor Spinning Mill's maka semakin tinggi pula tingkat work engagement karyawan di PT. Pamor Spinning Mill's. Selain itu dari uji t yang telah dilakukan diketahui bahwa self determination juga memiliki pengaruh signifikan secara parsial terhadap work engagement dengan nilai $t_{\text {hitung }}$ sebesar 2,158.

Hasil penelitian ini mendukung hasil penelitian yang telah dilakukan oleh Meyer dan Gagne (2008 : 3), yang menyatakan bahwa selfdetermination mendukung konsep teori workengagement.

\section{Pengaruh Job Performance terhadap Work Engagement}

Menurut Tika (2006 : 121) Kinerja (Job Performance) merupakan hasil-hasil fungsi pekerjaan seseorang yang dipengaruhi oleh berbagai faktor untuk mencapai tujuan organisasi dalam periode waktu tertentu. Job performance sangat berkaitan dengan work engagement karena apabila seorang karyawan memiliki work engagement atau keterikatan kerja, maka karyawan tersebut pastiakan mengedepankan kinerja nya dalam melakukan pekerjaannya. Sehingga dapat dikatakan bahwa job performance atau kinerja karyawan berbanding lurus dengan work engagement karyawan dalam suatu perusahaan.

Menurut hasil analisis yang telah dilakukan pada penelitian ini dapat diketahui bahwa terdapat pengaruh signifikan antara Job Performnce terhadap Work Engagementkaryawan PT. Pamor Spinning Mill's. Melalui hasil dari analisis linier berganda di dapat nilai koefisien regresi yang positif untuk variabel Job Performance terhadap Work Engagement karyawan di PT. Pamor Spinning Mill's. Hal tersebut dapat diartikan bahwa semakin tinggi Job Performance pada karyawan PT. Pamor Spinning Mill's maka semakin tinggi pula tingkat work engagement karyawan di PT. Pamor Spinning Mill's. Selain itu dari uji t yang telah dilakukan menyatakan bahwa Job Performance juga memiliki pengaruh signifikan secara parsial terhadap work engagement dengan nilai $t_{\text {hitung }}$ yang lebih besar dari nilai $t_{\text {tabel }}$ yakni sebesar 3.356.

Hasil penelitian ini mendukung hasil penelitian yang telah dilakukan oleh Auzi Annisa (2013 : 16), yang menyatakan bahwa Job Performance dan workengagementsaling berpengaruh secara signifikan.

\section{Pengaruh Quality of Worklife, Self Determination dan Job Performance terhadap Work Engagement}

Hasil analisis yang telah diuji tersebut, mendukung teori yang telah dikemukakan oleh Bakker, A. B, Demerouti, E. (2008 : 209) bahwa terdapat beberapa faktor yang mempengaruhi keterikatan kerja yaitu; sumber daya kerja, sumber personal, dan tuntutan kerja. Dalam penelitian ini, Quality of Worklife dapat mencerminkan faktor sumber daya kerja. 
Sedangkan self determination mencerminkan faktor sumber personal, dan Job Performance mencerminkan faktor tuntutan kerja. Sehingga analisis dalam penelitian ini sesuai dengan teori Bakker dan Demerouti.

Pernyataan tersebut dapat diketahui kebenarannya dari hasil uji $\mathrm{F}$ yang telah dilakukan. Menurut hasil uji $\mathrm{F}$ yang telah dianalisis sebelumnya, diketahui bahwa Ho ditolak dan $\mathrm{H}_{4}$ diterima karena hasil $\mathrm{F}_{\text {hitung }}>\mathrm{F}_{\text {tabel }}$ (2.70) yakni sebesar 25,428 dengan tingkat signifikansi $\mathrm{P}_{\text {value }}<0.05$. Hal ini membuktikan bahwa terdapat pengaruh secara simultan yang memang nyata terjadi (signifikan) dan tidak diperoleh secara kebetulanantara quality of work life, self determination, dan Job Performance terhadapWork Engagement Karyawan pada PT. Pamor Spinning Mill's di Karanganyar.

\section{Penutup}

Terdapat pengaruh yang signifikan secara parsial maupun secara simultan antara variabel independen penelitian dengan variabel dependen dari penelitian ini.Hal tersebut dapat diketahui melalui uji $t$ dan uji F yang telah dilakukan sebelumnya. Analisis yang telah dilakukan menunjukkan hasil yang signifikan positif dari seluruh variabel sehingga perusahaan perlu mempertahankan dan jika perlu meningkatkan ketiga variabel sehingga work engagement juga akan meningkat. Dalam penelitian selanjutnya diharapkan peneliti memberikan inovasi lain seperti menambahkan variabel yang lebih kompleks sehingga hasil bisa lebih bervariasi. Penelitian selanjutnya diharapkan memperluas ruang lingkup penelitian dan memperbanyak responden dari berbagai perusahaan. Penelitian selanjutnya diharapkan dapat menggunakan survey yang lebih bervariasi (tidak hanya menggunakan kuesioner) seperti dengan metode wawancara secara langsung agar penelitian bisa mendapatkan jawaban dan hasil yang lebih rinci dari hasil penelitian yang menggunakan satu metode saja.

\section{Daftar Pustaka}

Annisa, A. (2013). Pengaruh employee engagement terhadap Kinerja Karyawan PT. Chandra Sakti Utama Leasing Jakarta. Universitas Indonesia.

Bakker, A. B, Damerouti, E. (2008). Towards a Model of Work Engagement. Career Development International, 13, 3, 209-223.

Devi, E. K. D. (2009). Analisis pengaruh kepuasan kerja dan motivasi terhadap kinerja karyawan dengan komitmen organisasional sebagai variabel Intervening. Universitas Stuttgart, 109-115.

Fallis, A. . (2013). Pengaruh Kepercayaan kepada pemimpin terhadap work engagement. Journal of Chemical Information and Modeling, 53(9), 1689-1699. https://doi. org/10.1017/CBO9781107415324.004

Fatimah, H., Dharmawan, A. H., Sunarti, E., \& Affandi, M. J. (2015). Pengaruh Faktor Karakteristik Individu dan Budaya Organisasi terhadap Keterikatan Pegawai Generasi X dan Y. Jurnal Aplikasi Manajemen, 13(3), 402-409. Retrieved from http://www. jurnaljam.ub.ac.id/index.php/jam/article/view/786/740

Fitria, D. (2012). Kualitas Kehidupan Kerja dan Kinerja. Retrieved from https://derafitria. wordpress.com/2012/9/29/kualitas-kehidupan-kerja-dan-kinerja/

Ghozali, I. (2009). Aplikasi Analisis Multivariative dengan Program SPSS. Semarang: Badan Penerbit UNDIP.

Hariandja, M. T. E. (2007). Manajemen Sumber Daya Manusia Pengadaan, Pengembangan, Pengkompensasian dan Peningkatan Produktivitas Pegawai. Jakarta: Grasindo. 
Mangkunegara, A. A. P. (2009). Evaluasi Kinerja SDM. Bandung: PT. Remaja Rosda.

Mangkuprawira. (2011). Keterikatan Karyawan Pada Perusahaan. Retrieved December 1, 2016, from http://ronawajah.wordpress.com/2011/01/12/keterikatan-karyawanpadaperusahaan/

Manik, D. A. (2015). Pengaruh Kualitas Kehidupan Kerja (Quality of Work Life) dan Kepuasam Kerja Terhadap Keterikatan Karyawan (Employee Engagement), 15.

Meyer, J. P. \& Gagne, M. (2008). Employee Engagement From a Self-Determination Theory Perspective. Industrial and Organizational Psycology, 1, 60-62.

Mujiasih, E \& Ratnaningsih, I. Z. (2012). Meningkatkan Work Engagement melalui Gaya kapemompinan transformational dan budaya organisasi. Retrieved from http://eprints. unisbank.ac.id/464/1/artikel-55.pdf

Mujiasih, E., \& Ratnaningsih, I. Z. (2007). Meningkatkan Work Engagement Melalui Gaya Kepemimpinan Transformational dan Budaya Organisasi, 1-20. https://doi. org/10.4324/9780203853047

Pitoyo, D. J. (2015). Keterkaitan antara transformational leadership, meaning in work, leader member exchange (LMX), job performance dan work engagement. Universitas Sebelas Maret.

Polii, L. R. G. (2015). Analisis Keterikatan Karyawan terhadap Pekerjaan dan Lingkungan Kerja terhadap Kepuasan Kerja dan Turnover Intentions Karyawan Di Rumah Sakit Siloam Manado, 3(4), 178-190.

Ramirez. (2007). resilience: a concept analysis. Nursing Forum, 42.

Risher. (2010). Don't overlook frontline supervisors. Public Manager, 39, 74-76.

Rose, Raduan Che, Loosee Bech, J. U. and K. I. (2006). An Analysis of Quality Work of Life and Caree-Related Variables. American Journal of Applied Science, 3(12), 2151-2159.

Saks., A. M. \& G. J. A. (2014). What do we really Know about Employee Engagement? Journal of Human Resource Development Quarterly, 25, 155-182.

Saraji,. G. Nasl \& Dargahi, H. (2006). Study of Quality of Work Life (QWL). Irian Journal Public Health, 35, 8-14.

Sasono, A. D. D. \& A. D. (2015). Pengaruh Sumberdaya Pekerjaan (Job Resourcs) dengan Keterikatan Kerja (Work Engagement) sebagai mediator terhadap perilaku proaktif. Jurnal Manajemen Magistra, 1.

Sugiyono. (2011). Statistika untuk Penelitian. Bandung: Alfabeta.

Sugiyono. (2012). Metode Penelitian Bisnis. Bandung: Alfabeta.

Sumakto, Windy Auliah, S. (2013). Hubungan Keterikatan Kerja dengan Kinerja pada Karyawan Hotel Surabaya Plaza. Jurnal Psikologi Industri Dan Organisasi, 2.

Suwatno, Y. T. dan. (2008). Manajemen Sumber Daya Manusia. Bandung: Alfabeta.

Tahir, R. (2012). Kualitas kehidupan kerja, perilaku kewargaan organisasional, dan keterikatan karyawan.

Thoha, M. (2010). Perilaku Organisasi Konsep Dasar dan Aplikasinya. Jakarta: PT. Raja.

Tika, M. (2006). Budaya Organisasi dan Peningkatan Kinerja Perusahaan.Jakarta: Bumi Aksara. 


\section{LAMPIRAN 7}

\section{Hasil Uji Asumsi Klasik}

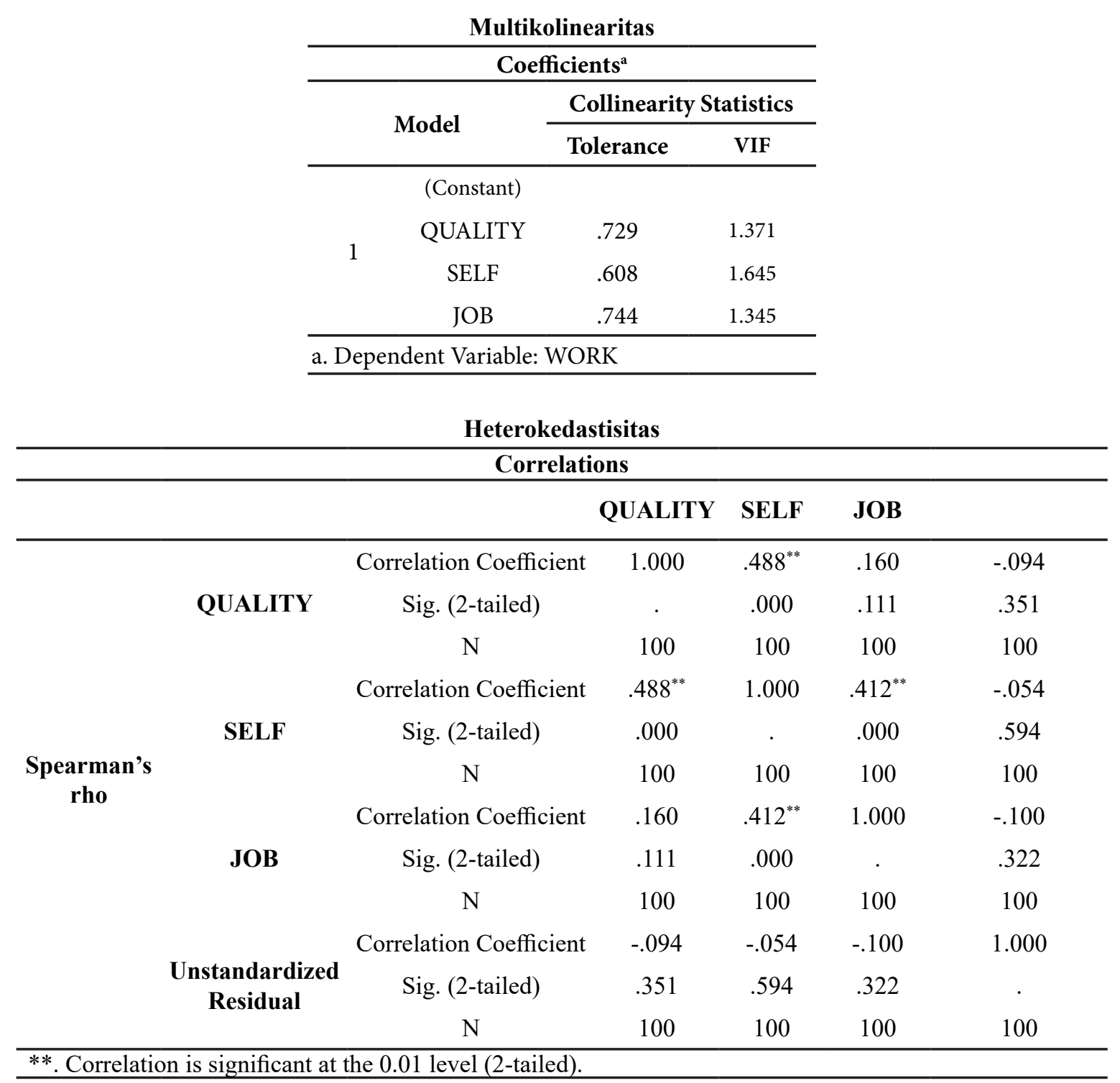

Normalitas

NPar Tests

\begin{tabular}{llc}
\hline \multicolumn{3}{c}{ One-Sample Kolmogorov-Smirnov Test } \\
\hline & $\mathbf{N}$ & $\begin{array}{c}\text { Unstandardized } \\
\text { Residual }\end{array}$ \\
\hline \multirow{2}{*}{ Normal Parameters ${ }^{\mathrm{a}}$} & Mean & $\mathbf{1 0 0}$ \\
& Std. Deviation & .0000000 \\
& Absolute & 2.00371702 \\
Most Extreme Differences & Positive & .085 \\
& Negative & .051 \\
Kolmogorov-Smirnov Z & & -.085 \\
Asymp. Sig. (2-tailed) & & .854 \\
\hline a. Test distribution is Normal. & .459 \\
\hline
\end{tabular}




\section{LAMPIRAN 8}

Hasil Analisis Regresi Linier Berganda

Regression

\begin{tabular}{cccc}
\hline \multicolumn{4}{c}{ Variables Entered/Removed $^{\mathbf{b}}$} \\
\hline \multirow{2}{*}{ Model } & $\begin{array}{c}\text { Variables } \\
\text { Entered }\end{array}$ & $\begin{array}{c}\text { Variables } \\
\text { Removed }\end{array}$ & Method \\
\hline \multirow{2}{*}{1} & $\begin{array}{c}\text { JOB, QUALITY, } \\
\text { SELF }\end{array}$ &. & Enter \\
\hline
\end{tabular}

a. All requested variables entered.

b. Dependent Variable: WORK

\begin{tabular}{ccccccc}
\hline \multicolumn{7}{c}{ ANOVA $^{\mathrm{b}}$} \\
& Model & Sum of Squares & df & Mean Square & F & Sig. \\
\hline \multirow{2}{*}{1} & Regression & 315.837 & 3 & 105.279 & 25.428 & $.000^{\mathrm{a}}$ \\
& Residual & 397.473 & 96 & 4.140 & & \\
& Total & 713.310 & 99 & & & \\
\hline
\end{tabular}

a. Predictors: (Constant), JOB, QUALITY, SELF

b. Dependent Variable: WORK

\begin{tabular}{|c|c|c|c|c|c|c|}
\hline \multicolumn{7}{|c|}{ Coefficients $^{\mathrm{a}}$} \\
\hline & \multirow{2}{*}{ Model } & \multicolumn{2}{|c|}{ Unstandardized Coefficients } & \multirow{2}{*}{$\begin{array}{c}\begin{array}{c}\text { Standardized } \\
\text { Coefficients }\end{array} \\
\text { Beta }\end{array}$} & \multirow{2}{*}{$\mathbf{t}$} & \multirow{2}{*}{ Sig. } \\
\hline & & B & Std. Error & & & \\
\hline \multirow{4}{*}{1} & (Constant) & 4.716 & 2.103 & & 2.242 & .027 \\
\hline & QUALITY & .290 & .077 & .334 & 3.747 & .000 \\
\hline & SELF & .322 & .149 & .211 & 2.158 & .033 \\
\hline & JOB & .413 & .123 & .297 & 3.356 & .001 \\
\hline
\end{tabular}

a. Dependent Variable: WORK 